\title{
Asymmetric Cellulosic Membranes: Current and Future Aspects
}

\author{
Tuerxun Duolikun ${ }^{1,2}$, Nadiah Ghazali ${ }^{1,2}$, Bey Fen Leo ${ }^{2,3}$, Hwei Voon Lee ${ }^{2}$, Chin Wei Lai ${ }^{2, *}$ (i) \\ and Mohd Rafie Bin Johan ${ }^{2, *}$ \\ 1 Department of Mechanical Engineering, Faculty of Engineering, University of Malaya, Kuala Lumpur 50603, \\ Malaysia; dolqun@um.edu.my (T.D.); diyaghaz@um.edu.my (N.G.) \\ 2 Nanotechnology \& Catalysis Research Centre (NANOCAT), Institute for Advanced Studies, \\ University of Malaya, Kuala Lumpur 50603, Malaysia; beyfenleo@um.edu.my (B.F.L.); \\ leehweivoon@um.edu.my (H.V.L.) \\ 3 Faculty of Medicine, University of Malaya, Kuala Lumpur 50603, Malaysia \\ * Correspondence: cwlai@um.edu.my (C.W.L.); mrafiej@um.edu.my (M.R.B.J.)
}

Received: 14 May 2020; Accepted: 1 July 2020; Published: 13 July 2020

check for updates

\begin{abstract}
In this paper, we report our attempt to elaborate on cellulose-based materials and their potential application in membrane science, especially in separation applications. Furthermore, the cellulosic membrane has received attention for potential use as biomaterials such as novel wound-dressings and hemodialysis materials. In this mini-review, we mainly focus on the separation and antimicrobial properties of cellulosic membranes and the advanced synthesis/processing methods for superior functional quality for various potential applications. Finally, we conclude with the market and the impact of developments of future expectations.
\end{abstract}

Keywords: asymmetry; cellulose; membrane; application

\section{Introduction}

Since the first successful development of asymmetric membranes by Leob and Sourirajan in the 1960s, the asymmetrical membrane (AM) has gained much attention due to its excellent properties compared to traditional symmetric membranes in various fields of material science [1]. An asymmetric membrane is morphologically unique because it combines a thin separation layer (skin) with a high permeable support layer. The skin layer is very thin $(0.1$ to $1 \mu \mathrm{m})$ and dense and lies on top of a thicker (100 to $200 \mu \mathrm{m})$ and porous support. Both layers are made of the same materials, performed and fabricated in the same process [2,3].

An extensive range of research and development (R\&D) regarding the fabrication and characterization of AMs is readily available. AMs can be fabricated from a wide selection of materials, such as ceramics, composites, and biocomposites [4-6]. However, this mini-review on AMs focuses explicitly on the cellulosic contents, along with the development of the AM for commercialization. Employing up-to-date information can be a great asset in forecasting the future trends of AMs and adjusting the current R\&D strategy from the traditional membrane to AMs.

At the moment, there are several challenges in the area of developing highly efficient and cost-effective AMs that are environmentally friendly, with sustainable development goals for application to switchable separation, biomedical, and energy-related industries.

\section{Cellulose}

Plant biomass is generally made up of three major organic fractions: lignin, cellulose, and hemicellulose. Cellulose is the main component that is composed of long chains of dimer units 
called cellobiose [7]. The most important properties of cellulose include a microfibrillated structure, which consists of both crystalline and amorphous regions (hierarchical), and its highly cohesive nature is attributed to the three hydroxyl groups in the cellobiose monomer that are able to form strong hydrogen bonds [8,9]. Cellulose also has distinguishing characteristics that are better than conventional polymers, including an excellent mechanical outline, renewable, biocompatible, and adaptable surface chemistry, and appealing optoelectronic features. Most cellulosic materials are extracted from plants, and a few small portions are from animals or bacteria. Cellulose is one of the most applicable and abundant natural biopolymeric materials suitable for the development of diverse nanomaterials. Due to growing environmental concerns, cellulosic materials have been widely promoted.

As human living standards continue to rise due to expeditious industrial developments, along with serious side effects, environmental pollution also rises from a mixture of air and water contamination. As a result, these common pollutants, either directly or indirectly, will cause critical health problems. Nanocellulose is synthesized from renewable, natural biopolymers that are free from any harmful pollutants. Based on its synthesis and preparation method, two main types of nanocellulose, shown in Figure 1, can be distinguished: (i) cellulose nanofibers (CNFs) and (ii) cellulose nanocrystals (CNCs) [9]. Cellulose nanofibers (CNFs) are favored for filtration applications because of their imposing ratio (surface area to volume) and higher strength [10].

One of the relevant nanocellulose applications is the development of water treatment filtration systems. Nowadays, energy-based industries are highly dependent on the extracted crude oils. Rising concerns due to oil pollution and frequent oil spills have made water and oil emulsion extractions a paramount issue. As the oil necessarily needs to be separated from its water content before any usage, an efficient oil-water separation technique is a challenge that we face over the good stability and viscosity of unrefined emulsions [10]. This could be addressed by employing CNF membrane technology.

The latest separation technologies are reported to have boosted efficiency and minimized clogging with the eco-friendly, renewable cellulosic membrane. A novel CNF hydrogel is a sustainable and reliable material for the modification of paper filters for water/oil separation. It has been increasingly manufactured because it can be smoothly progressed and applied to filtration applications. The distinctiveness of those filters lies in the hydrophilic/oleophobic performance arising from cellulosic properties and structure on a micro-scale, without having to introduce harmful substances. Besides being hazard-free, decreasing fouling and clogging could prolong the lifetime of filters. The recent studies on the CNF-based filter promised a soaring efficiency of above $99 \%$, and flux of $89.6 \mathrm{~L} / \mathrm{m}^{2} \mathrm{~h}$, with favorable commercial and preferable environmental footprints in separation applications [11].

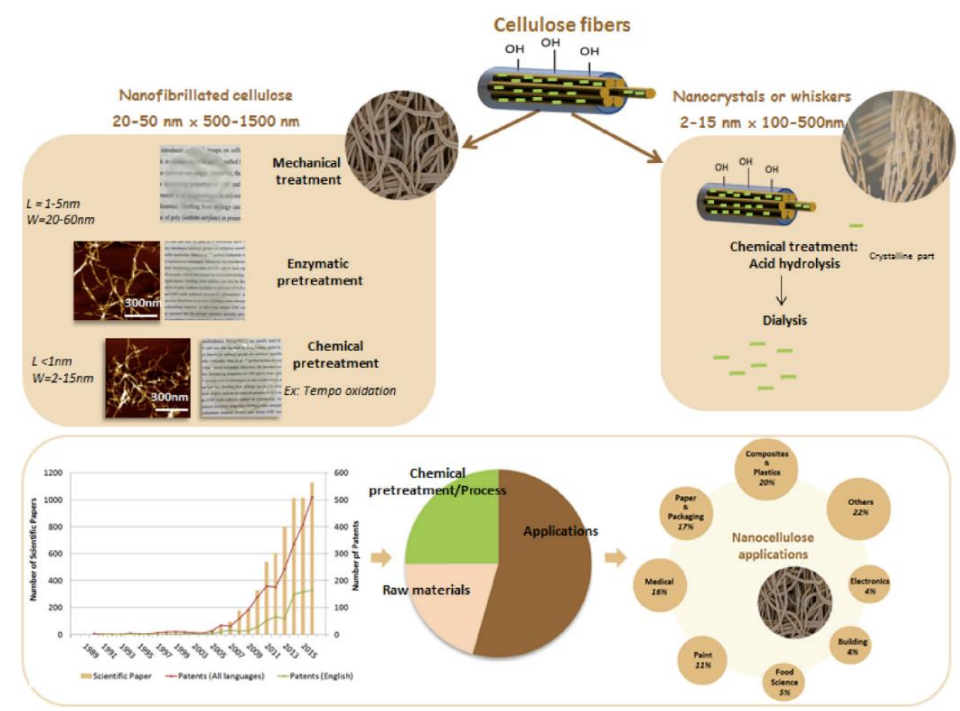

Figure 1. Two types of nanocellulose, cellulose nanocrystals (CNCs) and cellulose nanofibers (CNFs), can be extracted from the cellulose microfibrils [12]. 


\section{Cellulose Acetate}

In 1865, cellulose acetate (CA) was initially prepared as the acetate ester of cellulose. In order to be nonflammable and more inexpensive for manufacturing, the traditional nitrate film was displaced by CA in the middle of the last century [13]. CA has excellent chemical resistance, biocompatibility, and biodegradability, which is significantly important for biomedical applications such as antibacterial membranes for potential wound dressings [14].

$\mathrm{CA}$ is the most common acetate ester. It is also (rarely) called acetylated cellulose (AC) or xylonite [15]. The structural formula of CA, shown in Figure 2, is a cellulose section alongside two acetyl groups to each of glucose module.

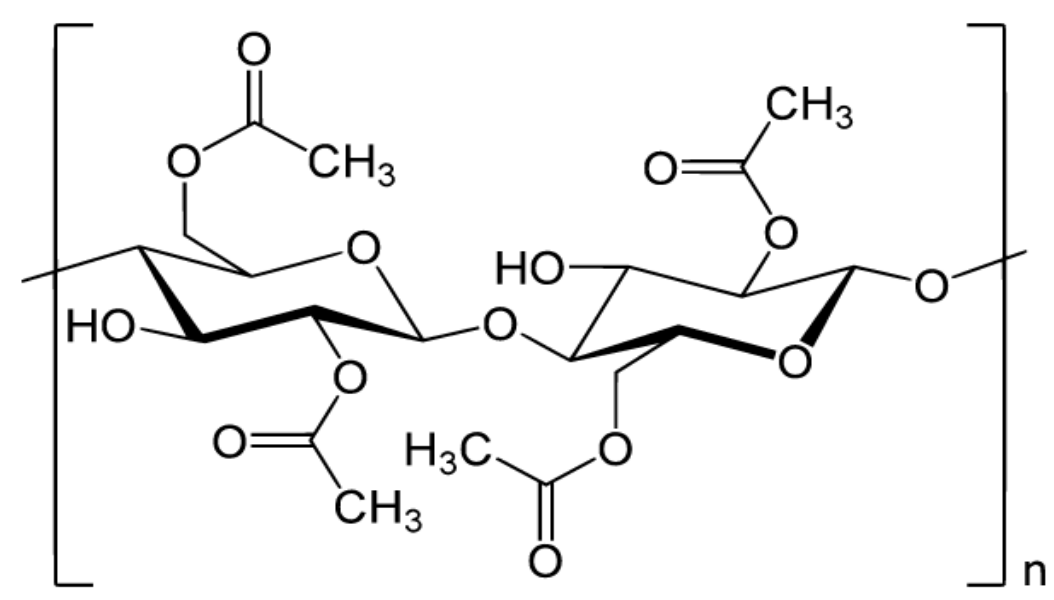

Figure 2. Chemical structure of cellulose acetate [15].

CA is utilized as photographic films, X-ray films, adhesives components, eyeglass frames, applied as filter parts of cigarettes, playing cards, handles of a sort of screwdriver, and reservoirs of pens [15].

\section{Cellulosic Asymmetric Membranes}

AM is one of the main types of membranes, which can be divided into three structures:

- $\quad$ Porous skin layer integral asymmetric.

- Thin dense skin layer integral asymmetric.

- Composites with thin-film structures [16].

Cellulosic asymmetric membranes (CAMs) include CA-based, CNF-based, or nanocrystalline cellulose (CNC)-based asymmetrical membranes, which are more advanced than commercialized membranes. CAM is extensively applied for reverse osmosis, ultra/microfiltration, novel gas separation, thermo-controlled wearable textiles, building insulation, as well as useable for specific army equipment [16-18].

In the 1960s, CA asymmetric membranes were developed for seawater desalination by Loeb and Sourirajan [19]. We summarize the cellulosic membranes in Table 1 for a comparative study. 
Table 1. Advantages of the cellulosic membrane and targeted applications.

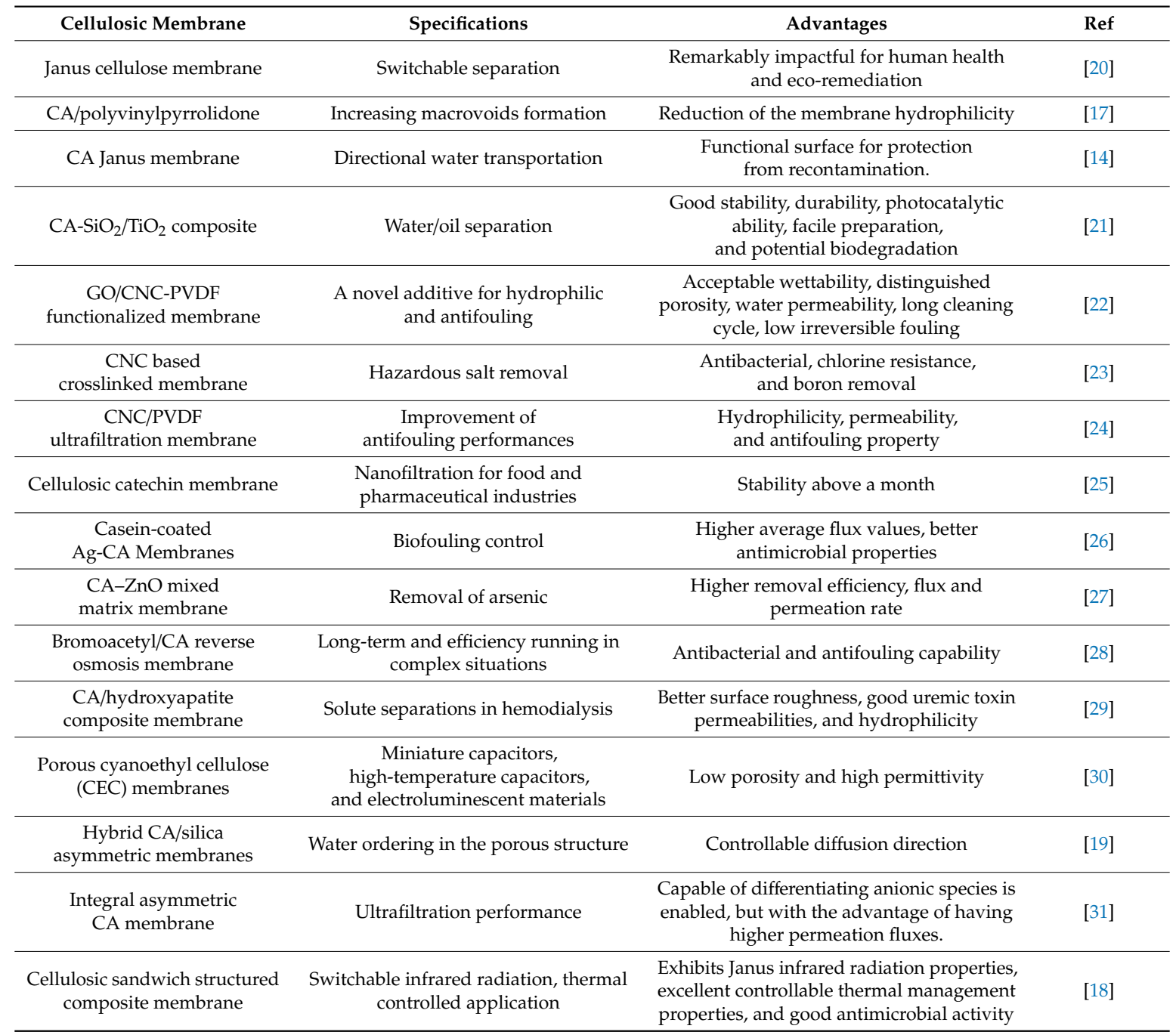

\section{Other Asymmetric Membranes}

Asymmetric polyetherimide membranes (APEMs) are one of the AMs for nanofiltration of organic molecules with appreciable high flux. APEMs exhibit good refusal for hydrophilic molecules, such as polyethylene glycol (PEG) between 400 to 6000 Dalton, while in regards to molecular weight, $79-100 \%$ organic rejection of aqueous solutions with $500 \mathrm{ppm}$ was achieved [32].

\section{Synthesis and Processing Methods}

\subsection{Synthesis of Nanocellulose}

CNC: The raw lignocellulosic biomass is subjected to pretreatment to remove impurities from fiber cell walls [33]. In short, after grinding, extracted cellulose (EC) fibers can be obtained via alkaline hydrolysis and bleaching process. The hydrolysis process can be completed through $\mathrm{H}_{2} \mathrm{SO}_{4}$ or $\mathrm{HCl}$ [34]. Then, the suspension will be dialyzed with distilled water for a few days and freeze-dried $[35,36]$.

CNF: The process includes the delignification and removal of hemicellulose from lignocellulosic biomass. First of all, the fibers are treated with $\mathrm{NaClO}_{2}$ aqueous solution, and later, oven-dried. The conventional method for hemicellulose removal is by pretreatment using $\mathrm{KOH}$ at ambient temperature. Then, the fibers are washed in distilled water and dried in a vacuum oven overnight. In the end, the product is milled for at least 25 cycles via a homogenous mill machine [37]. 
Both synthesis methods can produce nano-sized cellulose products. However, CNCs give highly crystallized features compare to CNFs, and morphological examination shows bigger lengths of CNFs while similar widths with CNCs [38].

\subsection{Asymmetrical Membrane}

Generally, phase inversion (PI) is the most common procedure to produce AMs. The exchange will appear between the casting solution film (solvent) and the precipitating medium (nonsolvent) while a substrate is absorbed into a coagulation bath, and finally, this might lead to phase separation. Producing the CAM by the PI method with dimethyl sulfoxide (solvent) has been a success. The selection of dimethyl sulfoxide is due to its comparatively low vital toxicity and biodegradability. Thus, dimethyl sulfoxide is known as a more eco-friendly solvent for the production of CAMs [39].

Most common synthesis steps of CAMs are as below:

- Extraction of cellulose from biomass: pure cellulose can be extracted by multistage chemical and mechanical purification methods [38].

- CA synthesis: produced via the reaction of extracted cellulose with acetic anhydride under the catalysis process $\left(\mathrm{H}_{2} \mathrm{SO}_{4}\right)$ [40].

- Production of CAMs: asymmetric CA membranes were produced by the PI method, as discussed above [41].

In other studies, the fabrication of antifouling and antibacterial polyethersulfone/CNC membranes was synthesized with a nonsolvent PI method [42].

\section{Applications}

The general approaches for the contaminant separation/removal from solutions are through adsorption, precipitation, electrochemical oxidation, chemical dispersion, biological degradation, foam fractionation, centrifugation, and separation methods [27]. In this mini-review, we mainly focus on membrane technology, especially CAMs and their applications.

\subsection{Effective Separation}

The filtration of spoilt liquefied pollutants has been found to be an advantageous separation technique in the petrol-chemical industries [32]. The wastewater from worldwide industrial and economic development has become a critical environmental issue that is alarming to the health of humans [21]. For the last few decades, besides the enormous expansion of offshore oil exploitation and consumption of the petroleum industry, the frequency of oil-spill incidents has increased and affected marine eco-systems and natural resources. The common treatment methods for industrial wastewater have a process that is complicated, not cost-effective, and can produce subordinate pollution, as well as showing an in-vain effect for emulsions of droplets with smaller diameters $(<20 \mu \mathrm{m})$. Importantly, it is not uncommon that this treatment has difficulty in demonstrating the demulsification phenomenon under natural conditions and complications [20].

Wastewater treatment approaches are accountable for the separation of pollutants via filtration methods [32]. Lately, bio-based separation materials have been concentrated on owing to their biodegradability, good film-forming capacity, and uncomplicated modification features [21]. Furthermore, assorted membrane materials dependent on super wettability have been fully developed for separation treatments. As a case in point, a super-hydrophilic/oleophobic polyvinylidene fluoride membrane fabricated thorough an in-situ crosslinking copolymerization approach showed good efficiency on separation and superlative recyclability performance for oil-in-water emulsions. Hence, specific membrane materials that can ascertain the switchable separation for both oil-in-water and water-in-oil emulsions are most desirable [20].

The current global challenge is switchable membrane technology (oil-in-water and water-in-oil) with high efficiency and speedy separations [43]. The simple mechanism of the switchable membrane 
technology illustrated in Figure 3. This kind of efficient separation is not only noteworthy for human health but also fundamental for eco-remediation. That being so, the immobilization and modifying process of the Janus cellulose membrane (JCM) has been demonstrated to have the desired wettability and antibacterial properties. Over the conventional procedure, silver nanoparticles (NPs) were immobilized on the membrane surface, while the other side of the membrane was treated for subsequent hydrophobic modification. The JCM had an excellent hydrophobic feature on one side, and conversely, the other side was hydrophilic. Remarkably, the JCM demonstrated exceptional performance for switchable separation, with more than $96.0 \%$ effectiveness. The JCM demonstrated amazing recyclability, while the efficiency and flux showed minimal variations over ten cycles of separation. The JCM can be further developed for the productions of separation material for possible commercialization with industrial strategies [20]. Meanwhile, $\mathrm{ZnO} / \mathrm{MnO}_{2}$ hybrid $\mathrm{CAM}$ for effective separations was recently reported, which has an inclusion of anisotropic wettability, effective separations, cost-efficiency, and environmentally friendly features. This form of hybrid CAM is an emerging candidate for assorted potential applications, especially for industrial wastewater management [43].

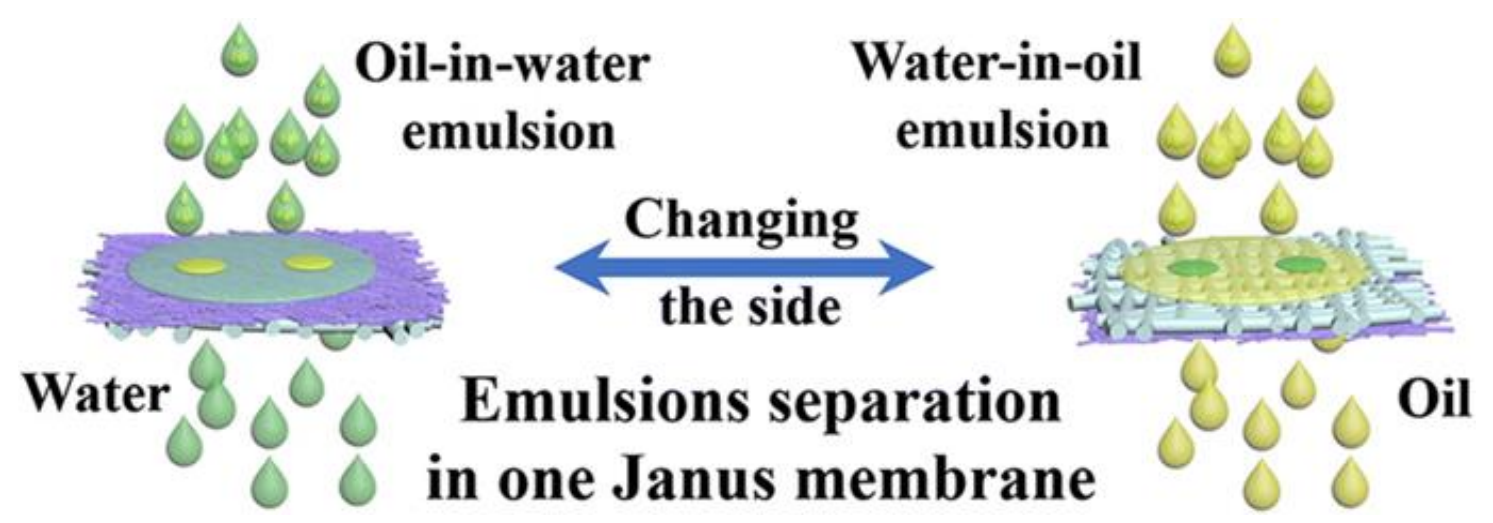

Figure 3. Efficient and rapid separation of various surfactant-stabilized oil-in-water and water-in-oil emulsions [43].

Cellulose is a widely abundant natural material with a crosslinked structure and a cost-efficient, eco-friendly, and sustainable nature. It presents promising applicability in wastewater management. However, the application of cellulosic materials is restricted by its surface chemistry and bacterial degradation. Therefore, its wettability, together with antibacterial features, are appreciable assets for the separation of industrial wastewater [20].

A specific CAM with wettability and other functions was fabricated, and the functionalized CAM demonstrated antibacterial/antimicrobial properties suitable for practical environments [20].

Petroleum industries have been producing a large amount of wastewater that has high contaminants that include dissolved solids, petrol-organic contents, and other oily substances. Modifications of CAMs that could enhance the hydrophilicity for functionalized membranes in wastewater treatments, with improved antifouling performance without lowering its pollutant rejection, have been reported [44]. In other studies, a mixed matrix CAM was fabricated by alternating the formations of CA, acetone, and formamide toward the synthesis of exotic filter membranes, with/without NPs, for arsenic/synthetic separation.

\subsection{Membrane Bioreactors}

Membrane bioreactors (MBs) are a combination of a filtration process such as micro/nanofiltrations with biological treatments that are used for municipal and industrial wastewater treatments. MBs possess several outstanding points in comparison with general conventional methods, particularly on the environmental impact, sludge production reductions, the finest effluent, and complete biomass retention without a secondary clarifier [22]. In these circumstances, reducing the biofouling in MBs was 
achievable by the strategical orientation of easing the certain fouling on the membrane, namely, aeration scouring, physio-chemical cleaning, and surface modification (hydrophilicity, negative potential, porosity, as well as morphology) [22]. For example, the modified CAM was fabricated via a typical PI approach comprising functionalized cellulosic GO/PVDF composites. As a result, the cellulosic composite enhanced hydrophilicity, permeability, stability, and antifouling characters on the modified PVDF membranes [22].

Modified polymer/NP compositions can reach the needed outcomes through the evolution of targeted membranes over charge changes, structural remodeling, and by adjusting the porosities. The modified CAM with silver NPs was achieved by the use of surface chemistry, which was motivated by the Ag affinity to the bacteria. Due to the scattered Ag NPs on the surface of the modified CAM, it promises a substantial elimination of bacteria accumulation [26].

Alternatively, a polyethersulfone-based CAM was developed for its selectivity to protein-in-water separation and antifouling/antibacterial features to Staphylococcus aureus and is identifiable by the halo-zone evident around the CAM [42].

\subsection{Wound Healing}

The drawbacks of readily available wound healing dressings (WHDs) are outlined by their lack of water permeability, which induces exudate accumulation, tissue maceration, inflammation, or infections [45]. However, a porous structure in wound dressings would increase water evaporation (causing wound dehydration) and, more importantly, the inability to prevent bacteria penetration, which leads to infection. This would further damage the wound areas [46].

The shortcomings call for a more advanced development of WHDs and CAMs, which can pose a promising alternative to overcome this issue. The denser outer layer of AMs is responsible for keeping the wound safe against external risks, acting as a barrier similar to the skin's epidermis layer, while the more porous interior layer acts as a template for coordinating cell adhesion, migration, and proliferation. Figure 4 shown the ideal structure of multifunctional AM for wound healing. Despite the potential, properties like porosity, wettability, transmission rate, mechano-physical character, antimicrobial activity, and water uptake must be fulfilled before it can be employed [46].

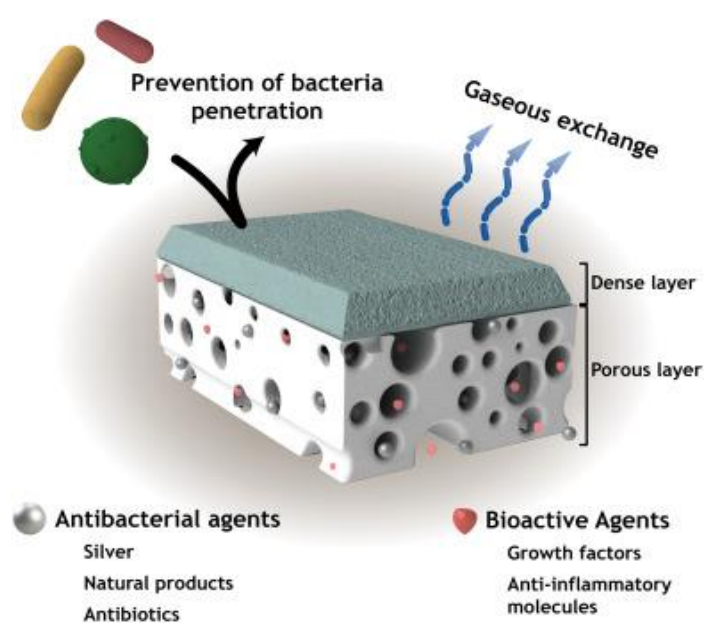

Figure 4. Asymmetric membrane for wound healing [46].

One of the recent achievements in this area is the development of a chitosan/poly(vinyl pyrrolidone)/nanocellulose bio-nanocomposite asymmetry membrane. The membrane was fabricated via a salt leaching route with the addition of 3 and $5 \%$ wt nanocellulose. It was found that the incorporation of nanocellulose into the composite enhances the antibacterial activity. Besides that, the asymmetric bio-nanocomposite also exhibited excellent in vitro cytocompatibility, which enabled a faster wound healing, thus, showing great potential in wound healing applications $[46,47]$. 


\subsection{Asymmetric Supercapacitors}

Developing a practical and efficient cellulosic membrane for energy-efficient devices is significantly crucial to solving the current energy crisis as well as to prevent global warming [18]. Over the last few years, the advancement of portable/wearable electronic devices has gained more attention, especially in the development of supercapacitors. A supercapacitor has higher energy, good power density, and a long-run lifetime and is compact, lightweight, and flexible. Asymmetric supercapacitors (ASs) are the latest type of energy storage device assembled from positive and negative electrodes of different voltage windows. The CNF/MWCNT/RGO/Fe $\mathrm{F}_{3} \mathrm{O}_{4}$ composite is soundly designed and fabricated for functionalized ASs with significant advantages. The CNF components in the supercapacitors act as additives and are a reinforcement for the nanocarbon materials. They have excellent flexibility, film-forming ability, and the ability to facilitate nanocarbon material dispersion. The CNFs efficiently prevent the agglomeration of MWCNTs and RGO nanosheets while facilitating the formation of a porous 3D structure. Highly developed 3D structures facilitate ion diffusion, resulting in improved conductivity. The well-designed AS demonstrated excellent cycle stability by maintaining more than $90 \%$ of its initial capacitance over 5000 cycles [48].

\subsection{Energy Conversion}

Thermal energy (TE) is a common heat source and can be commonly categorized as high-grade $\left(>650{ }^{\circ} \mathrm{C}\right)$, medium grade $\left(200\right.$ to $\left.277^{\circ} \mathrm{C}\right)$, and low-grade heat $\left(<100{ }^{\circ} \mathrm{C}\right)$, which is often wasted. Low-grade heat is abundant and usually originates from power plants and manufacturing industries [49]. Membrane distillation (MD) and thermo-osmotic energy conversion (TOEC) might be the answer to utilize this low-grade heat [50]. TOEC is a relatively new innovation that has promising prospects in managing low-grade TE [51]. The water vapor that diffuses across the membrane condenses in a pressurized reservoir, turning into a stream of water that is used to produce electricity [52].

AMs are essential for distillation and energy conversation procedures to achieve high permeability and liquid entry pressure. The mechanism of AMs for energy conversion application shown in Figure 5. A recent study showed that a modified asymmetric mixed-cellulose membrane with pore diameters of 50 and $25 \mathrm{~nm}$ had an exceptional liquid entry pressure of $>24$ bar. The lower structure comprises of large pores which facilitates vapor permeability, while the thin upper layer contains smaller pores to prevent the membrane from wetting. The study demonstrated that asymmetric membranes have high liquid-entry pressure (LEP) while maintaining high vapor flux, which is essential for both MD and TOEC [53].

\subsection{Hemodialysis}

For past two decades, dialysis materials have gained more attention for potential applicability to kidney failure diseases (KFDs) and hence rapidly industrialized. However, the availability of advanced treatments under hospitalization faced challenges according to the annual mortality rate statistics, which is estimated at $18 \%$ at a constant rate. More than that, better cost-efficiency of biocompatible membranes for hemodialysis is urgently required to meet the affordability requirement for patients with KFDs. Hemodialysis is a secure purification method that posed good results within other methods, particularly peritoneal dialysis and organ transplantation [29]. 


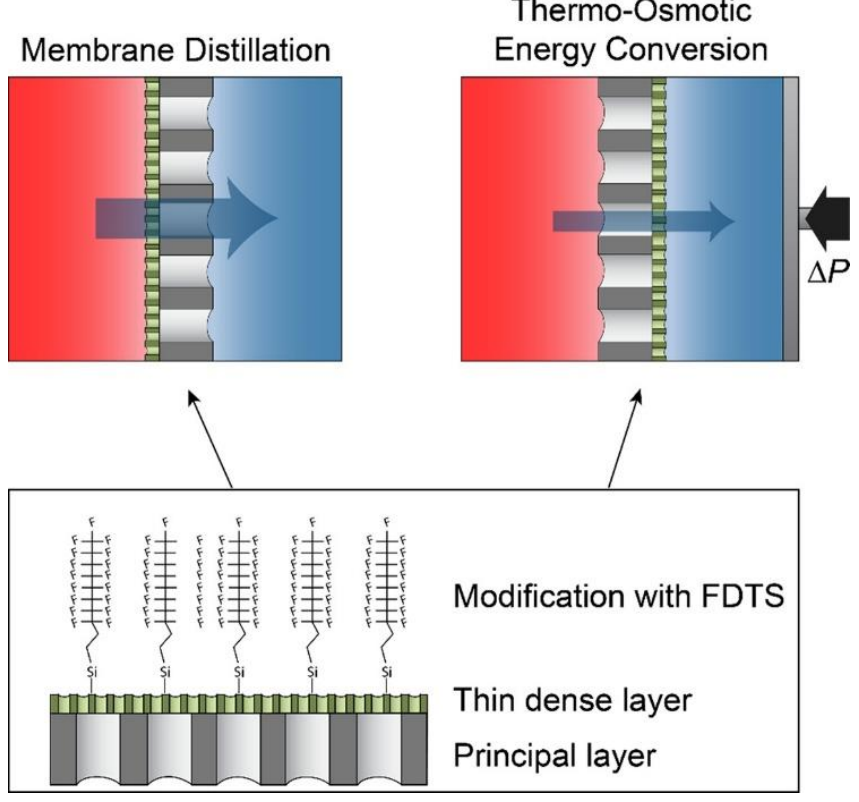

Figure 5. Asymmetrical membrane for distillation and heat-wasted energy conversion [53].

A successful dialysis remedy based on the biocompatible artificial membrane was placed inside a hemodialyzer. In comparison with a conventional symmetric membrane, the modified cellulose triacetate (CTA) for the biocompatible AM was achieved by the basic mechanism of blood interaction on a smooth surface. The novel CTA, strengthened by the physio-chemical characteristics of the blood-exposed membrane surface, together with important properties of the CAM, could further lead to progressive remedies of hemodialysis [54].

Indeed, cellulose is not new to the fabrication of traditional symmetric hemodialysis membrane materials. However, CTA membranes with asymmetric structures were, most recently, established through the spinning method [55]. ACT high flux dialyzers are one of the best examples for hemodialysis with excellent comparability. The significant features of hemodialysis membranes could be affected by blood-membrane interactions, especially low transporting resistance [56]. Ahead of clinical application, it is necessary to clarify the relationship between pore size, structure, and surface chemistry on the characteristics of the developed membranes for hemodialyzers [57].

\section{Summary}

In this mini-review, we focused on the cellulosic asymmetric membrane for current applications, as well as discussing possible improvements. As asymmetric membranes have excellent wettability, porosity, hydrophilicity, permeability, and antifouling/antimicrobial properties, these properties make it a much-desired material for various potential applications and commercial approaches, especially in water purification and desalination, as well as biomedical applications. Thus, the cellulosic asymmetric membrane has a huge potential market and impact on sustainable development in the future by, for example, improving the surface chemistry of AMs for switchable separations or applying voltages to reform the surface charge of AMs to induce ion current to electro-osmotic flow rectification [58]. For the wound healing applications of composite-based AMs, deep studies on the antibacterial properties, porosity, cell adhesions, cytotoxicity, and histological examinations are needed. 
Author Contributions: All authors contributed to the paper. Conceptualization: M.R.B.J. and C.W.L.; writing-original draft: T.D.; editing: N.G., H.V.L. and B.F.L. All authors have read and agreed to the published version of the manuscript.

Funding: This research work was financially supported by the University Malaya Research Grant DANA TOP 100 NANOCAT (TOP100PDNANOCAT) and the Impact-Oriented Interdisciplinary Research Grant (No. IIRG018-2019).

Conflicts of Interest: The authors declare no conflict of interest.

\section{References}

1. Loeb, S.; Sourirajan, S. Sea Water Demineralization by Means of an Osmotic Membrane. Adv. Chem. 1963, 38, 117-132. [CrossRef]

2. Ismail, A.; Yean, L.P. Review on the development of defect-free and ultrathin-skinned asymmetric membranes for gas separation through manipulation of phase inversion and rheological factors. J. Appl. Polym. Sci. 2003, 88, 442-451. [CrossRef]

3. Jiang, L.Y. Asymmetric Membrane. In Encyclopedia of Membranes; Drioli, E., Giorno, L., Eds.; Springer: Berlin/Heidelberg, Germany, 2016.

4. Chen, X.; Gao, X.; Fu, K.; Qiu, M.; Xiong, F.; Ding, N.; Cui, Z.; Wang, Z.; Fan, Y.; Drioli, E. Tubular hydrophobic ceramic membrane with asymmetric structure for water desalination via vacuum membrane distillation process. Desalination 2018, 443, 212-220. [CrossRef]

5. Tsydenov, D.; Parmon, V.; Vorontsov, A. Toward the design of asymmetric photocatalytic membranes for hydrogen production: Preparation of $\mathrm{TiO}_{2}$-based membranes and their properties. Int. J. Hydrog. Energy 2012, 37, 11046-11060. [CrossRef]

6. Shan, D.; Yang, J.; Liu, W.; Yan, J.; Fan, Z. Biomass-derived three-dimensional honeycomb-like hierarchical structured carbon for ultrahigh energy density asymmetric supercapacitors. J. Mater. Chem. A 2016, 4, 13589-13602. [CrossRef]

7. Jung, S.-J.; Kim, S.-H.; Chung, I.-M. Comparison of lignin, cellulose, and hemicellulose contents for biofuels utilization among 4 types of lignocellulosic crops. Biomass Bioenergy 2015, 83, 322-327. [CrossRef]

8. Meng, F.; Wang, G.; Du, X.; Wang, Z.; Xu, S.; Zhang, Y. Extraction and characterization of cellulose nanofibers and nanocrystals from liquefied banana pseudo-stem residue. Compos. Part B Eng. 2019, 160, 341-347. [CrossRef]

9. Lavoine, N.; Desloges, I.; Dufresne, A.; Bras, J. Microfibrillated Cellulose-Its barrier properties and applications in cellulosic materials: A review. Carbohydr. Polym. 2012, 90, 735-764. [CrossRef]

10. Barhoum, A.; Li, H.; Chen, M.; Cheng, L.; Yang, W.; Dufresne, A. Emerging Applications of Cellulose Nanofibers. In Handbook of Nanofibers; Springer Nature Switzerland AG: Basel, Switzerland, 2019; pp. 1131-1156.

11. Rohrbach, K.; Li, Y.; Zhu, H.; Liu, Z.; Dai, J.; Andreasen, J.; Hu, L. A cellulose based hydrophilic, oleophobic hydrated filter for water/oil separation. Chem. Commun. 2014, 50, 13296-13299. [CrossRef]

12. Rol, F.; Belgacem, M.N.; Gandini, A.; Bras, J. Recent advances in surface-modified cellulose nanofibrils. Prog. Polym. Sci. 2019, 88, 241-264. [CrossRef]

13. Cellulose Acetate. Available online: https://en.wikipedia.org/wiki/Cellulose_acetate (accessed on 21 March 2020).

14. Wu, J.; Qiu, Q.; Wang, Y.; Zhang, H.; Qin, X. Asymmetric water affinity on antibacterial electrospun sub-micro cellulose acetate Janus membrane. Mater. Lett. 2019, 256, 126607. [CrossRef]

15. McKeen, L.W. Film Properties of Plastics and Elastomers; William Andrew is an imprint of Elsevier: Oxford, UK; Cambridge, MA, USA, 2017.

16. Buonomenna, M.G. Design Next Generation Membranes or Rethink the "Old" Asymmetric Membranes? Symmetry 2020, 12, 270. [CrossRef]

17. Saljoughi, E.; Mohammadi, T. Cellulose acetate (CA)/polyvinylpyrrolidone (PVP) blend asymmetric membranes: Preparation, morphology and performance. Desalination 2009, 249, 850-854. [CrossRef]

18. Gu, B.; Liang, K.; Zhang, T.; Yue, X.; Qiu, F.; Yang, D.; Chen, M. Fabrication of sandwich-structured cellulose composite membranes for switchable infrared radiation. Cellulose 2019, 26, 8745-8757. [CrossRef] 
19. Beira, M.J.; Da Silva, M.P.; Condesso, M.; Cosme, P.; Almeida, P.L.; Corvo, M.C.; Sebastião, P.J.; Figueirinhas, J.; De Pinho, M.N. Molecular order and dynamics of water in hybrid cellulose acetate-silica asymmetric membranes. Mol. Phys. 2018, 117, 975-982. [CrossRef]

20. Lv, Y.; Li, Q.; Hou, Y.; Wang, B.; Zhang, T. Facile Preparation of an Asymmetric Wettability Janus Cellulose Membrane for Switchable Emulsions' Separation and Antibacterial Property. ACS Sustain. Chem. Eng. 2019, 7, 15002-15011. [CrossRef]

21. Yang, X.; Ma, J.; Ling, J.; Li, N.; Wang, D.; Yue, F.; Xu, S. Cellulose acetate-based $\mathrm{SiO}_{2} / \mathrm{TiO}_{2}$ hybrid microsphere composite aerogel films for water-in-oil emulsion separation. Appl. Surf. Sci. 2018, 435, 609-616. [CrossRef]

22. Lv, J.; Zhang, G.; Zhang, H.; Yang, F. Graphene oxide-cellulose nanocrystal (GO-CNC) composite functionalized PVDF membrane with improved antifouling performance in MBR: Behavior and mechanism. Chem. Eng. J. 2018, 352, 765-773. [CrossRef]

23. Asim, S.; Wasim, M.; Sabir, A.; Shafiq, M.; Andlib, H.; Khuram, S.; Ahmad, A.; Jamil, T. The effect of Nanocrystalline cellulose/Gum Arabic conjugates in crosslinked membrane for antibacterial, chlorine resistance and boron removal performance. J. Hazard. Mater. 2018, 343, 68-77. [CrossRef]

24. Lv, J.; Zhang, G.; Zhang, H.; Zhao, C.; Yang, F. Improvement of antifouling performances for modified PVDF ultrafiltration membrane with hydrophilic cellulose nanocrystal. Appl. Surf. Sci. 2018, 440, 1091-1100. [CrossRef]

25. Abdellah, M.H.; Pérez-Manríquez, L.; Puspasari, T.; Scholes, C.A.; Kentish, S.; Peinemann, K.-V. A catechin/cellulose composite membrane for organic solvent nanofiltration. J. Membr. Sci. 2018, 567, 139-145. [CrossRef]

26. Sprick, C.; Chede, S.; Oyanedel-Craver, V.; Escobar, I.C. Bio-inspired immobilization of casein-coated silver nanoparticles on cellulose acetate membranes for biofouling control. J. Environ. Chem. Eng. 2018, 6, 2480-2491. [CrossRef]

27. Durthi, C.P.; Rajulapati, S.B.; Palliparambi, A.A.; Kola, A.K.; Sonawane, S.H. Studies on removal of arsenic using cellulose acetate-zinc oxide nanoparticle mixed matrix membrane. Int. Nano Lett. 2018, 8, 201-211. [CrossRef]

28. Fei, P.; Liao, L.; Meng, J.; Cheng, B.; Hu, X.; Song, J. Synthesis, characterization and antibacterial properties of reverse osmosis membranes from cellulose bromoacetate. Cellulose 2018, 25, 5967-5984. [CrossRef]

29. Hayder, A.; Hussain, A.; Khan, A.N.; Waheed, H. Fabrication and characterization of cellulose acetate/hydroxyapatite composite membranes for the solute separations in Hemodialysis. Polym. Bull. 2017, 75, 1197-1210. [CrossRef]

30. Wang, B.; Kang, H.; Yang, H.; Xie, J.; Liu, R. Preparation and dielectric properties of porous cyanoethyl cellulose membranes. Cellulose 2018, 26, 1261-1275. [CrossRef]

31. Figueiredo, A.S.; Garcia, A.R.; Minhalma, M.; Ilharco, L.; de Pinho, M. The ultrafiltration performance of cellulose acetate asymmetric membranes: A new perspective on the correlation with the infrared spectra. J. Membr. Sci. Res. 2019, 6, 70-80.

32. El-Gendi, A.; Favre, E.; Roizard, D. Asymmetric polyetherimide membranes (PEI) for nanofiltration treatment. Eur. Polym. J. 2018, 105, 204-216. [CrossRef]

33. Nascimento, D.M.d.; Almeida, J.S.; Vale, M.d.S.; Leitão, R.C.; Muniz, C.R.; Figueirêdo, M.C.B.d.; Morais, J.P.S.; Rosa, M.d.F. A comprehensive approach for obtaining cellulose nanocrystal fromcoconut fiber. Part I: Proposition of technological pathways. Ind. Crops Prod. 2016, 93, 66-75. [CrossRef]

34. Cranston, E.D.; Gray, D.G. Morphological and Optical Characterization of Polyelectrolyte Multilayers Incorporating Nanocrystalline Cellulose. Biomacromolecules 2006, 7, 2522-2530. [CrossRef]

35. Kargarzadeh, H.; Ahmad, I.; Abdullah, I.; Dufresne, A.; Zainudin, S.Y.; Sheltami, R.M. Effects of hydrolysis conditions on the morphology, crystallinity, and thermal stability of cellulose nanocrystals extracted from kenaf bast fibers. Cellulose 2012, 19, 855-866. [CrossRef]

36. do Nascimento, D.M.; Dias, A.F.; de Araújo Junior, C.P.; de Freitas Rosa, M.; Morais, J.P.S.; de Figueirêdo, M.C.B. A comprehensive approach for obtaining cellulose nanocrystal fromcoconut fiber. Part II: Environmental assessment of technologicalpathways. Ind. Crops Prod. 2016, 93, 58-65. [CrossRef]

37. Yasim-Anuar, T.A.T.; Ariffin, H.; Norrrahim, M.N.F.; Hassan, M.A. Factors Affecting Spinnability of Oil Palm Mesocarp Fiber Cellulose Solution for the Production of Microfiber. Bioresources 2016, 12, 715-734. [CrossRef]

38. Tuerxun, D.; Pulingam, T.; Nordin, N.I.; Chen, Y.W.; Bin Kamaldin, J.; Julkapli, N.B.M.; Lee, H.V.; Leo, B.F.; Johan, M.R.; Duolikun, T.; et al. Synthesis, characterization and cytotoxicity studies of nanocrystalline cellulose from the production waste of rubber-wood and kenaf-bast fibers. Eur. Polym. J. 2019, 116, 352-360. [CrossRef] 
39. Nu, D.T.T.; Hung, N.P.; Van Hoang, C.; Van Der Bruggen, B. Preparation of an Asymmetric Membrane from Sugarcane Bagasse Using DMSO as Green Solvent. Appl. Sci. 2019, 9, 3347. [CrossRef]

40. Meireles, C.D.S.; Filho, G.R.; Ferreira, M.F., Jr.; Cerqueira, D.; Assunção, R.M.N.; Ribeiro, E.A.M.; Poletto, P.; Zeni, M. Characterization of asymmetric membranes of cellulose acetate from biomass: Newspaper and mango seed. Carbohydr. Polym. 2010, 80, 954-961. [CrossRef]

41. Durmaz, E.N.; Culfaz-Emecen, P.Z. Cellulose-based membranes via phase inversion using [EMIM]OAc-DMSO mixtures as solvent. Chem. Eng. Sci. 2018, 178, 93-103. [CrossRef]

42. Zhang, D.; Karkooti, A.; Liu, L.; Sadrzadeh, M.; Thundat, T.; Liu, Y.; Narain, R. Fabrication of antifouling and antibacterial polyethersulfone (PES)/cellulose nanocrystals (CNC) nanocomposite membranes. J. Membr. Sci. 2018, 549, 350-356. [CrossRef]

43. Yue, X.; Zhang, T.; Yang, D.; Qiu, F.; Li, Z. Janus $\mathrm{ZnO}$-cellulose/ $\mathrm{MnO}_{2}$ hybrid membranes with asymmetric wettability for highly-efficient emulsion separations. Cellulose 2018, 25, 5951-5965. [CrossRef]

44. Kusworo, T.D.; Soetrisnanto, D.; Santoso, C.; Payanti, T.D.; Utomo, D.P. Hydrophylicity enhancement of modified cellulose acetate membrane to improve the membrane performance in produced water treatment. MATEC Web Conf. 2018, 156, 08003. [CrossRef]

45. Morgado, P.I.; Aguiar-Ricardo, A.; Correia, I.J. Asymmetric membranes as ideal wound dressings: An overview on production methods, structure, properties and performance relationship. J. Membr. Sci. 2015, 490, 139-151. [CrossRef]

46. Miguel, S.P.; Moreira, A.F.; Correia, I.J. Chitosan based-asymmetric membranes for wound healing: A review. Int. J. Boil. Macromol. 2019, 127, 460-475. [CrossRef]

47. Poonguzhali, R.; Basha, S.K.; Kumari, V.S. Novel asymmetric chitosan/PVP/nanocellulose wound dressing: In vitro and in vivo evaluation. Int. J. Boil. Macromol. 2018, 112, 1300-1309. [CrossRef]

48. Xia, L.Y.; Li, X.; Wu, X.; Huang, L.; Liao, Y.; Qing, Y.; Wu, Y.; Lu, X.; Yu, L. $\mathrm{Fe}_{3} \mathrm{O}_{4}$ nanoparticles embedded in cellulose nanofibre/graphite carbon hybrid aerogels as advanced negative electrodes for flexible asymmetric supercapacitors. J. Mater. Chem. A 2018, 6, 17378-17388. [CrossRef]

49. Gingerich, D.; Mauter, M.S. Quantity, Quality, and Availability of Waste Heat from United States Thermal Power Generation. Environ. Sci. Technol. 2015, 49, 8297-8306. [CrossRef]

50. Swaminathan, J.; Chung, H.W.; Warsinger, D.M.; Lienhard V, J.H. Membrane distillation model based on heat exchanger theory and configuration comparison. Appl. Energy 2016, 184, 491-505. [CrossRef]

51. Straub, A.P.; Yip, N.Y.; Lin, S.; Lee, J.; Elimelech, M. Harvesting low-grade heat energy using thermo-osmotic vapour transport through nanoporous membranes. Nat. Energy 2016, 1, 16090. [CrossRef]

52. Phillip, W.A. Under Pressure; Nature Publishing Group Macmillan Building: London, UK, 2016.

53. Shaulsky, E.; Karanikola, V.; Straub, A.P.; Deshmukh, A.; Zucker, I.; Elimelech, M. Asymmetric membranes for membrane distillation and thermo-osmotic energy conversion. Desalination 2019, 452, 141-148. [CrossRef]

54. Ronci, M.; Leporini, L.; Felaco, P.; Sirolli, V.; Pieroni, L.; Greco, V.; Aceto, A.; Urbani, A.; Bonomini, M. Proteomic Characterization of a New asymmetric Cellulose Triacetate Membrane for Hemodialysis. Proteom.-Clin. Appl. 2018, 12, e1700140. [CrossRef]

55. Togo, K.; Yamamoto, M.; Imai, M.; Akiyama, K.; Yamashita, A.C. Comparison of biocompatibility in cellulose triacetate dialysis membranes with homogeneous and asymmetric structures. Ren. Replace. Ther. 2018, 4, 29. [CrossRef]

56. Kim, T.R.; Hadidi, M.; Motevalian, S.P.; Sunohara, T.; Zydney, A.L. Effects of Plasma Proteins on the Transport and Surface Characteristics of Polysulfone/Polyethersulfone and Asymmetric Cellulose Triacetate High Flux Dialyzers. Artif. Organs 2018, 42, 1070-1077. [CrossRef]

57. Kim, T.R.; Hadidi, M.; Motevalian, S.P.; Zydney, A.L.; Sunohara, T. Transport Characteristics of Asymmetric Cellulose Triacetate Hemodialysis Membranes. Blood Purif. 2017, 45, 46-52. [CrossRef]

58. Martin, C.R.; Wu, X.; Martin, C.R. From Ion Current to Electroosmotic Flow Rectification in Asymmetric Nanopore Membranes. Nanomaterials 2017, 7, 445. [CrossRef]

(C) 2020 by the authors. Licensee MDPI, Basel, Switzerland. This article is an open access article distributed under the terms and conditions of the Creative Commons Attribution (CC BY) license (http://creativecommons.org/licenses/by/4.0/). 